\title{
The Acute
} Care Nurse Practitioner: An Established Role in Acute and Critical Care

\author{
Ruth M. Kleinpell
}

\section{Introduction}

Nurse practitioners (NPs) are registered nurses with a master's and or Doctoral degrees, advanced licensure, certification, and function as independent practitioners who practice in various health care settings, including ambulatory, acute, critical, and long-term care (American Academy of Nurse Practitioners [AANP], 2006). Although the original focus of advanced practice nursing care was to provide health promotion and disease prevention services in primary care, an increasing number of NPs are working in acute care settings. This is related to the increased acuity levels of hospitalized patients and the need for expert practitioners to assist in managing patients with complex health conditions. 
The acute care nurse practitioner (ACNP) role represents a unique opportunity for advanced practice in acute and critical care. According to the 2004 National Nurse Practitioner Sample Survey, approximately $4.5 \%$ of the NP population or more than 4,500 NPs are ACNPs (Goolsby, 2005). Since the formulation of the ACNP role, it has evolved into an established specialty area of NP practice.

\section{Origins of the Acute Care Nurse Practitioner Role}

The ACNP role evolved from the need to have an expert practitioner to provide care to patients with critical, acute illness as well as patients with critical, chronic illness. Driving forces in the evolution of the ACNP role included an increase in the severity of illness of hospitalized patients, reduction in hospital lengths of stay, increase in the aging population with chronic conditions, increase in demands for care, access to care issues, and changes in medical residency coverage in the hospital setting (Steel, 1997).

Similar to the evolution of the neonatal NP role in the late 1970s, the ACNP role developed in response to residency shortages in the intensive care unit (ICU) (Keeling \& Bigbee, 2005). As medical education became more sensitive to the long hours required by interns and residents, the acute care facilities sought alternatives to promote ongoing effective care for their patients. The nurses who had expertise as primary providers were ideally suited to attain the additional knowledge and skills to meet the complex needs of these patients. Keane and Richmond (1993) were among the first to document the role of the inpatient NP in acute care, a role that was predominantly focused on patient care in the ICU and hospital setting.

There were several significant milestones in the development of the ACNP role. The formulation of annual conferences addressing the educational preparation of ACNPs was a crucial element to organize and unify the essential elements for this advanced practice specialty. In 1993, the transition began and existing bodies of nursing, including the American Nurses Association, American Association of Colleges of Nursing, American Association of Critical Care Nurses, and the state's Boards of Nursing, sought to address specific clinical practice 
issues. The first national certification and the publication of the ACNP scope and standards followed in 1995. The development of ACNP specialty competencies occurred in 2004, including research expectations and publications, highlighting the expansion and growth of the role. These developments substantiated the ACNP as a distinct specialty of advanced nursing practice. Exhibit 1.1 outlines some of the historical developments related to the ACNP role.

\begin{tabular}{|c|c|}
\hline 14 & $\begin{array}{l}\text { Historical Developments of the Acute Care } \\
\text { Nurse Practitioner (ACNP) Role }\end{array}$ \\
\hline Year & Event \\
\hline $1980 s-1990$ & $\begin{array}{l}\text { Literature reports and publications on inpatient nurse } \\
\text { practitioner roles }\end{array}$ \\
\hline 1992-1993 & Development of first ACNP educational programs \\
\hline 1993 & $\begin{array}{l}\text { First ACNP Consensus Conference held in Boston, with } 40 \text { attendees } \\
\text { to discuss issues related to ACNP education and training }\end{array}$ \\
\hline 1993 & Published reports on ACNP educational programs and curriculum \\
\hline 1994 & $\begin{array}{l}\text { Second ACNP Consensus Conference held in Cleveland, with } \\
80 \text { attendees to discuss issues related to ACNP education and } \\
\text { training }\end{array}$ \\
\hline 1995 & $\begin{array}{l}\text { Scope of practice for the ACNP, published by the American } \\
\text { Nurses and the American Association of Critical Care Nurses }\end{array}$ \\
\hline 1995 & $\begin{array}{l}\text { First National Certification for ACNP, offered by the American } \\
\text { Nurses Credentialing Center }\end{array}$ \\
\hline 1995 & $\begin{array}{l}\text { Third Annual ACNP Consensus Conference held in Rochester } \\
\text { New York, with more than } 100 \text { attendees }\end{array}$ \\
\hline 1996 & $\begin{array}{l}\text { Fourth Annual ACNP Consensus Conference held in Hartford, } \\
\text { Connecticut }\end{array}$ \\
\hline 1997 & $\begin{array}{l}\text { Book published pertaining to ACNP role (The Acute Care Nurse } \\
\text { Practitioner. Springer Publishing. 1997) }\end{array}$ \\
\hline 1997 & $\begin{array}{l}\text { Fifth Annual ACNP Consensus Conference held in Myrtle Beach, } \\
\text { South Carolina }\end{array}$ \\
\hline & (continued) \\
\hline
\end{tabular}




\section{Historical Developments of the Acute Care Nurse Practitioner (ACNP) Role (continued)}

\begin{tabular}{|c|c|}
\hline Year & Event \\
\hline 1998 & $\begin{array}{l}\text { Publication of first national survey on ACNP practice (Kleinpell, } \\
\text { R. M., AACN Clinical Issues) }\end{array}$ \\
\hline 1998 & $\begin{array}{l}\text { Book published on ACNP practice issues (Practice Issues for } \\
\text { the Acute Care Nurse Practitioner. Kleinpell, R. M., \& } \\
\text { Piano, M. R. Springer Publishing. 1998) }\end{array}$ \\
\hline 1998 & $\begin{array}{l}\text { Sixth Annual ACNP Consensus Conference held in Pittsburgh, } \\
\text { Pennsylvania }\end{array}$ \\
\hline 1999 & $\begin{array}{l}\text { Publication of ACNP Certification Review Book (Acute Care Nurse } \\
\text { Practitioner Clinical Curriculum and Certification Review. } \\
\text { Gawlinski A, Hamwi, \& D. Philadelphia: WB Saunders) }\end{array}$ \\
\hline 1999 & $\begin{array}{l}\text { Publication of ACNP practice book (Principles of Practice for the Acute } \\
\text { Care Nurse Practitioner. Logan, P. Stamford: Appleton \& Lange) }\end{array}$ \\
\hline 1999 & $\begin{array}{l}\text { Publication of ACNP Certification Review Questions Book } \\
\text { (Miller, S. Health Leadership Associates) }\end{array}$ \\
\hline 1999 & Seventh Annual ACNP Consensus Conference held in Portland, Oregon \\
\hline 1999 & $\begin{array}{l}\text { Publication of National Longitudinal Survey on ACNP practice: } \\
\text { Year } 1 \text { (Kleinpell, R. AACN Clinical Issues) }\end{array}$ \\
\hline 2000 & $\begin{array}{l}\text { Eighth Annual ACNP Consensus Conference held in Chicago, } \\
\text { Illinois }\end{array}$ \\
\hline 2001 & $\begin{array}{l}\text { Book published on ACNP practice guidelines (Practice Guidelines } \\
\text { for Acute Care Nurse Practitioners. Barkley, T. W. \& Myers } \\
\text { C. M. Philadelphia: Saunders) }\end{array}$ \\
\hline 2001 & $\begin{array}{l}\text { Ninth Annual ACNP Consensus Conference held in Huntsville, } \\
\text { Alabama }\end{array}$ \\
\hline 2001 & $\begin{array}{l}\text { Publication of National Longitudinal Survey on ACNP practice: } \\
\text { Year } 2 \text { (Kleinpell, R. AACN Clinical Issues) }\end{array}$ \\
\hline 2002 & $\begin{array}{l}\text { Publication of certification review book (Acute Care Nurse } \\
\text { Practitioner Certification Examination Review Questions and } \\
\text { Strategies. Todd, B. Philadelphia: FA Davis) }\end{array}$ \\
\hline 2002 & $\begin{array}{l}\text { Tenth Annual Acute Care Nurse Practitioner Consensus Conference } \\
\text { held in Charlottesville, Virginia (last educator conference) }\end{array}$ \\
\hline 2002 & $\begin{array}{l}\text { Acute Care Interest Group Forum established at the American } \\
\text { Academy of Nurse Practitioners Conference }\end{array}$ \\
\hline
\end{tabular}




\begin{tabular}{|c|c|}
\hline Year & Event \\
\hline 2003 & $\begin{array}{l}\text { Acute Care Track established at the annual American Academy } \\
\text { of Nurse Practitioners Conference (transitioning of annual } \\
\text { ACNP Conference to National Nurse Practitioner Association) }\end{array}$ \\
\hline 2004 & $\begin{array}{l}\text { Publication of the Acute Care Nurse Practitioner Competencies, } \\
\text { National Panel for Acute Care Nurse Practitioner Competencies }\end{array}$ \\
\hline 2005 & $\begin{array}{l}\text { Publication of Acute care nurse practitioner practice: results of } \\
\text { a 5-year longitudinal study. (Kleinpell, R. American Journal of } \\
\text { Critical Care) }\end{array}$ \\
\hline 2005 & $\begin{array}{l}\text { Publication of nursing secrets series book on ACNP practice } \\
\text { (Acute Care Nurse Practitioner Secrets. Todd BA. St Louis: } \\
\text { Elsevier Mosby) }\end{array}$ \\
\hline 2005 & $\begin{array}{l}\text { Acute Care Column initiated in the Journal of the American } \\
\text { Academy of Nurse Practitioners }\end{array}$ \\
\hline 2005 & Acute Care Column initiated in the Journal Nurse Practitioner \\
\hline 2006 & $\begin{array}{l}\text { Publication of the revised ACNP Scope and Standards (Scope } \\
\text { and Standards of Practice for the Acute Care Nurse Practitioner, } \\
\text { American Association of Critical Care Nurses }\end{array}$ \\
\hline 2006 & $\begin{array}{l}\text { Publication on results of national survey of skills taught in } \\
\text { ACNP programs (Kleinpell et al. Nurse Practitioner) }\end{array}$ \\
\hline 2007 & $\begin{array}{l}\text { Second National Certification Exam becomes available from the } \\
\text { American Association of Critical Care Nurses }\end{array}$ \\
\hline 2008 & $\begin{array}{l}\text { Development and expansion of doctoral level (doctorate of } \\
\text { nursing practice) ACNP programs }\end{array}$ \\
\hline
\end{tabular}

\section{Acute Care Nurse Practitioner Role}

ACNPs have evolved and refined the role. Practice is not limited to the confines of the ICU and acute inpatient settings. ACNPs care for patients who are critically ill, regardless of the practice setting (Howie-Esquivel \& Fontaine, 2006). ACNPs are currently working in a wide variety of settings including hospitals, subacute care facilities, emergency departments, urgent care facilities, clinic settings, and various specialty practices. The ACNP's role has also evolved and now includes specialty tertiary care areas (e.g., interventional cardiology, interventional radiology, oncology, bone marrow transplant) and a growing number of specialty settings (e.g., the intensivist and hospitalist roles) (Kleinpell, et al., 2005). 
Although the ACNP role is recognized as a specialty area of NP practice, specific competencies were developed to reflect the knowledge base and scope of practice of ACNPs (National Panel for Acute Care Nurse Practitioner Competencies, 2004). The competencies outline essential role components, including assessment and diagnosis of complex acute, critical, and chronic health conditions and implementation of interventions to support patients with deteriorating physiologic conditions, including the application of basic and advanced life support and other invasive interventions or procedures to promote physiologic stability (National Panel for Acute Care Nurse Practitioner Competencies, 2004) (Exhibit 1.2).

The scope of practice for ACNPs identifies that the performance of noninvasive and invasive diagnostic and therapeutic interventional measures such as, but not limited to, EKG interpretation, radiographic interpretation, respiratory support, hemodynamic monitoring, central line and tube insertion, and lumbar puncture are within the scope of ACNP practice (National Panel for Acute Care Nurse Practitioner Competencies, 2004). The acute care practice setting involves the care of patients with acute and critical care conditions with high acuity levels. The ACNP may perform diagnostic and therapeutic measures to manage these significant health issues (National Panel for Acute Care Nurse Practitioner Competencies, 2004; Becker et al., 2006). This is a unique aspect of ACNP practice that is based on education, training, and specialty certification. A national survey of ACNP educational programs validated that the majority $(>55 \%)$ teach skills such as hemodynamic monitoring, suturing, central line insertion, and arterial puncture, which highlights the advanced skill set and training of ACNPs (Kleinpell et al., 2006).

The scope and standards of practice for the ACNP define the educational requirements needed for an ACNP. This enables advanced practice regulatory bodies to promote a universally comparable level of education. Graduates of ACNP programs should be able to comprehend and demonstrate advanced skills necessary to perform comprehensive health assessment, order and interpret diagnostic tests and procedures, use differential diagnosis, provide and evaluate outcomes of interventions for patients who are physiologically unstable, technologically dependent, and highly vulnerable for complications (American Association of Critical Care Nurses, 2006) (Table 1.1). 


\section{ACNP Specialty Competencies for Direct Clinical Practice}

\section{A. Assessment of Health Status}

1. Assesses the patients with complex acute, critical, and chronic illness for urgent and emergent conditions, using both physiologically and technologically derived data, to evaluate for physiologic instability and potentially life-threatening conditions

2. Obtains and documents a health history for patients with complex acute, critical, and chronic illness

3. Performs and documents complete, system-focused, or symptomspecific physical examinations on patients with complex acute, critical, and chronic illness

4. Assess the need for and performs additional screening, based on initial assessment findings

5. Performs evaluations for substance use, violence, neglect and abuse, barriers to learning, and pain

6. Distinguishes between normal and abnormal developmental and agerelated physiologic and behavioral changes in patients with complex acute, critical, and chronic illness

7. Assess for multiple interactive and synergistic effects of pharmacological agents, including over the counter preparations and alternative and complementary therapies, in patients with complex acute, critical, and chronic illness.

8. Assess the impact of an acute, critical and/or chronic illness or injury on the individual's: (a) health status (physical and mental), (b) functional status, including activity and mobility, (c) growth and development,

(d) nutritional status, (e) sleep and rest patterns, (f) quality of life,

(g) family, social, and educational relationships

9. Provides for the promotion of health and protection form disease by assessing for risks associated with the care of complex acute, critical, and chronic illness, such as physiologic risk, including but not limited to immobility. impaired nutrition and immunocompetence, fluid and electrolyte imbalance. invasive interventions, therapeutic modalities, and diagnostic tests

10. Prioritizes data collection, according to the patient's immediate condition or needs, as a continuous proves $\mathrm{n}$ acknowledgement of the dynamic nature of complex acute, critical, and chronic illness.

11. Assesses the needs of families and caregivers of patients with complex acute, critical, and chronic illness 


\section{ACNP Specialty Competencies for Direct Clinical Practice (continued)}

\section{B. Diagnosis of Health Status}

1. Diagnoses acute and chronic conditions that may result in rapid physiologic deterioration or life-threatening instability

2. Manages diagnostic tests through ordering, interpretation, performance, and supervision in the assessment of patients with complex acute, critical, and chronic illness

3. Utilizes specialty-based technical skills in the performance of diagnostic procedures to confirm or rule out health problems

4. Synthesizes data from various sources to make clinical judgments and decisions about appropriate recommendations and treatments

5. Prioritizes health problems during complex acute, critical, and chronic illness

6. Formulates differential diagnoses by priority considering multiple potential mechanisms causing complex acute, critical, and chronic illness states

7. Distinguishes complications of complex acute, critical, and chronic illness considering multisystem health problems

8. Distinguishes common mental health and substance use or addictive disorder/disease, such as anxiety, depression, and alcohol and drug use, in the presence of complex acute, critical, and chronic illness

9. Reformulates diagnoses by priority based on new or additional assessment data and the dynamic nature of complex acute, critical, and chronic illness

\section{Plan of Care and Implementation of Treatment}

1. Formulates a plan of care to address complex acute, critical, and chronic health care needs that (a) integrates knowledge of rapidly changing pathophysiology of acute and critical illness in the planning of care and implementation of treatment, (b) prescribes appropriate pharmacologic and nonpharmacologic treatment modalities, and (c) utilizes evidence-based practice in planning and implementing care.

2. Implements interventions to support the patient with a rapidly deteriorating physiologic condition, including the application of basic and advanced life support and other invasive interventions or procedures to regain physiologic stability. 
3. Manages, through ordering, performance, interpretation, or supervision, (a) interventions that utilize technological devices to monitor and sustain physiologic function, (b) diagnostic strategies to monitor and sustain physiologic function and ensure patient safety, including but not limited to ECG interpretation, X-ray interpretation, respiratory support, hemodynamic monitoring. and nutritional support.

4. Performs therapeutic interventions to stabilize acute and critical health problems, such as suturing, wound debridement, tube and line insertion, and lumbar puncture.

5. Analyses the indications, contraindications, risk of complications, and cost-benefits of therapeutic interventions.

6. Manages the plan of care through evaluation, modification, and documentation according to the patient's response to therapy, changes in condition. and to therapeutic interventions to optimize patient's outcomes.

7. Manages the patient's response to life support strategies.

8. Manages pain and sedation for patients with complex acute, critical, and chronic illness. (a) Prescribes pharmacologic and nonpharmacologic interventions. (b) Monitor patient's response to sedation. (c) Evaluates patient's response to therapy and changes the plan of care accordingly.

9. Implements palliative and end-of-life care in collaboration with the family. patient (when possible), and other members of the multidisciplinary health care team.

10. Initiates appropriate referrals and performs consultations.

11. Assures that the plan of care is individualized, recognizing the dynamic nature of the patient's condition, reflecting the patient's and family's needs, and considering cost and quality benefits.

12. Coordinates interdisciplinary and intradisciplinary teams to develop or revise plans of care focused on patient and/or family concerns.

13. Incorporates health promotion, health protection and injury prevention measures into the plan of care within the context of the complex acute. critical, and chronic illness.

14. Facilitates the patient's transition between and within health care settings, such as admitting, transferring, and discharging patients.

Adapted from: National Panel for Acute Care Nurse Practitioner Competencies. (2004). Acute Care Nurse Practitioner Competencies. Washington, DC: National Organization of Nurse Practitioner Faculties. 


\section{Standards of Clinical Practice for the Acute Care Nurse Practitioner}

\section{Standards of ACNP Clinical Practice}

Standard I: Assessment

The ACNP generates, collects, and integrates data from a wide variety of sources to make clinical judgments and decisions about indicated orders, procedures, and treatments.

Standard II: Diagnosis

The ACNP diagnoses and prioritizes actual or potential health care problems as the basis for designing interventions for the restoration of health or to meet a patient's goals.

Standard III: Outcome Identification The ACNP assumes a leadership role in assuring that the patient and health care team identify expected outcomes of care as the basis for developing the interdisciplinary plan of care.

\section{Standard IV: Planning}

The ACNP develops a plan of care that prescribes interventions to attain expected outcomes for the patient with acute, critical, and complex needs.

Standard V: Implementation

The ACNP implements interventions identified in the interdisciplinary plan of care for the patient with acute. critical, and complex chronic illness

Standard VI: Evaluation

The ACNP evaluates the patient's progress toward attainment of expected outcomes.

\section{Standards of ACNP Professional Performance}

\section{Standard I: Professional Practice}

The ACNP evaluates his or her clinical practice in relation to institutional guidelines, professional practice standards, and relevant statutes and regulations.

Standard II: Education

The ACNP acquires and maintains current knowledge in advanced nursing practice.

Standard III: Collaboration

The ACNP collaborates with the patient, family, and other health care providers in patient care.

Standard IV: Ethics

The ACNP integrates ethical considerations into all areas of practice.

Standard V: Systems Management The ACNP develops and participates in organizational systems and processes promoting optimal patient outcomes.

Standard VI: Resource Utilization

The ACNP considers factors related to safety, effectiveness, and cost in planning and delivering care.

Standard VII: Leadership

The ACNP provides leadership in the practice setting and the profession.

Standard VIII: Collegiality

The ACNP contributes to the professional development of peers, colleagues, and others. 
Standard VII: Research

The ACNP continually explores scientific knowledge, identifies specific research priorities in practice, and strives to enhance knowledge and skills through participation in research studies and provision of evidence-based practice.
Standard IX: Quality of Practice

The ACNP systematically evaluates and enhances the quality and effectiveness of advanced nursing practice and care delivery across the continuum of acute care services.

Adapted from American Association of Critical Care Nurses (2006). Scope and standards of practice for the acute care nurse practitioner. Aliso Viejo. CA: Author.

\section{Considerations for Acute Care Practice: Regulation}

ACNP practice is regulated by individual state practice acts and ACNP scope and standards of practice. Regulatory authority over advanced practice is predominantly governed by the Board of Nursing within each state. The majority of states afford title protection for NP practice through the Board of Nursing with sole authority over NP practice and no statutory or regulatory requirements for physician collaboration, direction, or supervision (Phillips, 2007). Currently, in all but 6 of the 50 states, regulatory control of NP practice falls under the control of the Board of Nursing (American Academy of Nurse Practitioners, 2006). In five states (Florida, South Dakota, North Carolina, Virginia, and Massachusetts), NP practice is collaborative, regulated by both the Board of Nursing and Board of Medicine. Nurses in these states must enter into an agreement with a physician to fully engage in advanced practice. In two states (Illinois and Nebraska), NP practice is regulated by a separate advanced practice board (American Academy of Nurse Practitioners, 2006). Awareness of state practice regulations provides information regarding credentialing and privileging requirements and the need for specific physician "supervision." ACNP practice can include performance of invasive skills and implementation of life-sustaining therapies such as, but not limited to, chest tube insertion, arterial line placement, central line placement, intubation, percutaneous tracheostomy, percutaneous endoscopic gastric (PEG) tube placement, initiation and adjustment of mechanical ventilation, and interpretation of hemodynamic monitoring. 
Collaborative practice agreements outlining the ACNP scope of practice are important for defining, enacting, and review of specific aspects of advanced nursing practice.

\section{Considerations for ACNP Practice: Opportunities for Role Expansion}

Originally, the major focus of the ACNP role was unit-based, collaborative physician practice based or specialty practice based. Although this offered initial opportunities for ACNP practice, research depicts that there are now more ACNPs employed in collaborative and specialty-based practice (Kleinpell, et al., 2005). ACNPs are often employed by a hospital or health care system or hired in collaborative practice arrangements. Currently, hospitals remain the largest employer of ACNPs (Kleinpell \& Goolsby, 2006). Specialtybased practice in traditional inpatient hospital areas, such as cardiac surgery, neurology, pulmonary medicine, orthopedics, oncology, infectious disease, endocrinology, transplantation, general surgery, and trauma, remain a large practice base for ACNPs.Additional practice settings include ambulatory clinics, collaborative practices, and nontraditional practice areas such as holistic clinics, sports medicine, and correctional facilities. Collaborative practice models for ACNPs include the establishment of advanced practice roles as hospitalist, intensivist, and surgical first assistant positions. Opportunities for ACNP practice have tremendously expanded since the creation of national board specialty certification in acute care. ACNP certification validates the professional nursing expertise of the role and will be pivotal in the future expansion of this role.

\section{Considerations for ACNP Practice: Challenges to Practice}

Along with increasing opportunities for ACNP practice come challenges for practice including credentialing and privileging, ensuring clinical competency, promoting awareness of the role, ensuring practice based on existing scope of practice, education, and reimbursement issues. Petitioning for full credentials and privileges based on education and training and scope of practice, providing education regarding the 


\section{Strategies for Ensuring Clinical Competency in the ACNP Role}

Several strategies can be used to ensure clinical competency for NPs working in acute care. These include the following:

Education and training for acute care skills set

Credentialing and privileging for acute care skills

Preceptorship and mentorship with a collaborating physician to verify skill competency

Formal post-master's education for acute care

Certification through advanced courses such as the Society of Critical

Care Medicine's Fundamentals of Critical Care Support Course

Attendance at conference sessions focusing on skills, such as the

American Academy of Nurse Practitioner's annual conference

offering arterial and central line insertion workshops, and work

shops on chest tube insertion

Use of a formal log to verify clinical skills and procedures

Use of simulation laboratory

Incorporation of clinical and procedural skill sets within the acute care programs

Adapted from Melander S. et al., (2008). Journal of the American Academy of Nurse Practitioners, 20, 63-68.

role of the ACNP, and awareness of worth in terms of billable revenue will lead to continued role recognition and role acceptance (Hravnak, et al., 2008; Magdic, et al., 2005). Several mechanisms exist to ensure clinical competency for NPs working in acute care including continued education and training for acute care skill sets, specialty certification, credentialing, and privileging for acute care skills (Exhibit 1.3).

In addition to the strategies outlined by Melander et al. (2007), the importance of mentorship cannot be underestimated in the refinement and evolution of the ACNP role. The ACNPs, who adopted the initial roles and established the need for ongoing education and training, scrutiny of policy and legislative changes enabling additional scope of practice, were trailblazers. They serve as role models and provide mentorship and preceptorship opportunities for future generations of ACNPs. 
ACNPs are positively impacting outcomes for patient care in many clinical settings. An ongoing challenge for ACNPs is to demonstrate their direct contributions to patient care, patient and family education, nursing staff education and competence, as well as on traditional outcome measures such as costs of care. The value of the ACNP role has been demonstrated in several studies assessing outcomes of ACNP practice (Burns \& Earven, 2002; Hoffman, et al., 2005; Gawlinski, et al., 2001; Russell, et al., 2002; Rudy, et al., 1998; Sole, et al., 2001; Cooper, et al., 2002; Meyer and Miers, 2005, Garcias et al., 2003). ACNPs are noted to contribute to excellence in collaborative care, promote evidence-based practice, and impact patient care outcomes. Acute care nursing experts directly impact patient care through the provision of high quality, cost-effective care, improved patient satisfaction, reduced length of stay in acute care units, lower mortality rates, decreased nosocomial infection rates, decreased rates of skin breakdown, and reduced readmission rates.

\section{Summary}

The ACNP role is an ideal extension for the advanced practice nurse expert in acute and critical care specializations. Currently, nurses who have completed a master's level of education and specific advanced knowledge and skills, outlined by the ACNP scope of practice, serve complex patients in health care settings. In the future, it is anticipated that ACNP programs will adapt to doctoral levels for entry into practice. The Doctorate of Nursing Practice (DNP) concept was developed in response to the American Association of Colleges of Nursing's ([AACN], 2005) vision of advanced practice nursing entry-level practice at the doctorate level. Practice opportunities for the growing specialty area of ACNP practice will continue to increase because of the complex health care needs for patients with acute and chronic disease states. The ACNP role represents an exciting career trajectory to advance nursing practice in acute and critical care.

\section{References}

American Academy of Nurse Practitioners. (2006). Scope of practice for nurse practitioners. Washington, DC: Author.

American Academy of Nurse Practitioners. (2006). State regulatory and prescriptiveauthority. Washington, DC: Author. 
American Association of Colleges of Nursing AACN. (2005). The essentials of doctoral education for advanced practice nursing. Washington, DC: Author.

American Association of Critical Care Nurses. (2006). Scope and standards of practice for the acute care nurse practitioner. Aliso Viejo, CA: Author.

Barkley T. W., \& Myers C. M. (2001). Practice guidelines for acute care nurse practitioners. Philadelphia: WB Saunders.

Becker, D., Kaplow, R., Muenzen, P. M., \& Hartigan, C. (2006). Activities performed by acute and critical-care advanced practice nurses: American Association of Critical Care Nurses Study of Practice. American Journal of Critical Care, 15, 130-148.

Burns, S. M., \& Earven, S. (2002). Improving outcomes for mechanically ventilated medical intensive care unit patients using advanced practice nurses: A 6-year experience. Critical Care Nursing Clinics of North America, 14, 231-243.

Cooper, M. A., Lindsay G. M., Kinn S., \& Swann I. J. (2002). Evaluating emergency nurse practitioner services: a randomized controlled trial. Journal of Advanced Nursing, 40, 721-730.

Daly, B. F. (1997). The acute care nurse practitioner. New York: Springer Publishing.

Gawlinski A., \& Hamwi, D. (Eds.) (1999). Acute care nurse practitioner clinical curriculum and certification review. Philadelphia: WB Saunders.

Gawlinski, A., McCloy, K., \& Jesurum, J. (2001). Measuring outcomes in cardiovascular APN practice. In R. Kleinpell (Ed.). Outcome assessment in advanced practice nursing (pp. 131-188). New York: Springer.

Goolsby, M.J. (2005). 2004 AANP National Nurse Practitioner Sample Survey. Journal of the American Academy of Nurse Practitioners, 17, 337-341.

Garcias V. H., Sicoutris C. P., Meredith D. M., Haut E., et al. (2003). Critical care nurse practitioners improve compliance with clinical practice guidelines in the surgical intensive care unit. Critical Care Medicine 31, 12:A93.

Hoffman, L., Tasota, F., Zullo, T. G., Scharfenberg, C., \& Donahoe, M. P. (2005). A controlled trial of nurse practitioner-managed care in a sub acute medical intensive care unit. In review.

Howie-Esquivel, J., \& Fontaine, D. K. (2006). The evolving role of the acute care nurse practitioner in critical care. Current Opinion in Critical Care, 12, 609-613.

Hravnak, M., \& Kleinpell R. M. (2005). The acute care nurse practitioner. In A. B. Hamric, J. A. Spross, \& C. M. Hanson. Advanced practice nursing: An integrative approach. St. Louis: Elsevier, In Press.

Keane, A., \& Richmond, T. (1993). Tertiary nurse practitioners. Image Journal of Nursing Scholarship, 25(4), 281-284.

Keeling, A.W., \& Bigbee, J.L. (2005). The history of advanced practice nursing in the United States. In A. B. Hamric, J. A. Spross, \& C. M. Hanson. Advanced practice nursing: An integrative approach. New York: Elsevier Saunders.

Klein, T. A. (2005). Scope of practice and the nurse practitioner: Regulation, competency, expansion, and evolution. Retrieved July 01, 2005 from http://www.medscape.com/viewprogram/4188_pnt

Kleinpell, R. M. (2005). Acute care nurse practitioner practice: Results of a 5year longitudinal study. American Journal of Critical Care, 14, 211-219. 
Kleinpell, R. M., \& Goolsby, M. J. (2006). 2004 American Academy of Nurse Practitioner National Nurse Practitioner Sample Survey: Focus on acute care. Journal of the American Academy of Nurse Practitioners, 18, 393-394.

Kleinpell, R. M., \& Hravnak, M. M. (2005). Strategies for success in the acute care nurse practitioner role. Critical Care Nursing Clinics of North America, 17, 177-181.

Kleinpell, R. M., Hravnak, M., King, J., \& Miller, K. (2008). Post-masters certification programs for nurse practitioners: Population specialty role preparation. Journal of the American Academy of Nurse Practitioners, 20, 63-68.

Kleinpell, R. M., Hravnak, M., Werner, K. E., \& Guzman, A. (2006). Skills taught in acute care NP programs: A national survey. The Nurse Practitioner, 31, 7-13.

Kleinpell, R. M., Perez, D.F., \& McLaughlin, R. (2005). Educational options for acute care nurse practitioner practice. Journal of the American Academy of Nurse Practitioners, 17, 460-471

Logan P. (Ed.). (1999). Principles of Practice for the Acute Care Nurse Practitioner Stamford: Appleton \& Lange.

Magdic, K. S., Hravnak, M., \& McCartney, S. (2005). Credentialing for nurse practitioners: An update. AACN Clinical Issues, 16(1), 16-22.

Melander S. Kleinpell R. McLaughlin R. (2007) Ensuring clinical competency for NPs in acute care. Nurse Practitioner. 32(4):19-20.

Meyer, S. C., \& Miers L. J. ( 2005) Effect of cardiovascular surgeon and acute care nurse practitioner collaboration on postoperative outcomes. AACN Clinical Issues, 16, p.149-158

National Organization of Nurse Practitioner Faculties. (2005). A preceptor manual for NP programs, faculty, preceptors, and students. Washington DC: Author.

National Panel for Acute Care Nurse Practitioner Competencies. (2004). Acute aare nurse practitioner competencies. Washington, DC: National Organization of Nurse Practitioner Faculties.

Phillips, S. J. (2007). A comprehensive look at the legislative issues affecting advanced practice nursing. The Nurse Practitioner, 35, p.14-42.

Russell, D., VorderBruegge, M., \& Burns, S. M. (2002). Effect of an outcomesmanaged approach to care of neuroscience patients by acute care nurse practitioners. American Journal of Critical Care, 11, 353-364.

Rudy, E. B., Davidson, L. J., Daly, B., Clochesy, J. M., Sereika, S., Baldisseri, M., et al. (1998). Care activities and outcomes of patients cared for by acute care nurse practitioners, physician assistants, and resident physicians: A comparison. American Journal of Critical Care. 7, 267-281.

Sole, M. L., Hunkar-Huie, A. M, Schiller, J. S., \& Cheatham, M. L. (2001). Comprehensive trauma patient care by nonphysician providers. AACN Clinical Issues, 12, 438-446.

Steel, J. E. (1997). Development of the acute care nurse practitioner role: Questions, opinions, consensus. In B. J. Daly (Ed.), The acute care nurse practitioner. New York: Springer.

Todd, B. (2002). Acute Care Nurse Practitioner Certification Examination: Review Questions and Strategies. Philadelphia: FA Davis.

Todd, B. A. (2005). Acute Care Nurse Practitioner Secrets. St Louis: Elsevier Mosby. 